\begin{tabular}{|c|l|}
\hline Title & $\begin{array}{l}\text { The crystal azimuth dependence of the angular distribution of the desorption flux of carbon dioxide produced on } \\
\text { pall ladium (110) surfaces }\end{array}$ \\
\hline Author(s) & Matsushima, Tatsuo \\
\hline Citation & $\begin{array}{l}\text { The Journal of Chemical Physics, 91(9), 5722-5730 } \\
\text { https://doi.org/10.1063/1.457526 }\end{array}$ \\
\hline Issue Date & 1989 \\
\hline Doc URL & http://hdl.handle.net/2115/5517 \\
\hline Rights & Copyright $\odot 1989$ A merican Institute of Physics \\
\hline Type & article \\
\hline File Information & JCP91-9.pdf \\
\hline
\end{tabular}

Instructions for use 


\title{
The crystal azimuth dependence of the angular distribution of the desorption flux of carbon dioxide produced on palladium (110) surfaces
}

\author{
Tatsuo Matsushima a) \\ Research Institute for Catalysis, Hokkaido University, Sapporo 060, Japan
}

(Received 24 January 1989; accepted 24 July 1989)

\begin{abstract}
The reaction of $\mathrm{CO}(\mathrm{a})$ and $\mathrm{O}(\mathrm{a})$ on $\mathrm{Pd}(110)$ was studied with LEED and angle-resolved thermal desorption. Heating the coadlayer produces five peaks in the $\mathrm{CO}_{2}$ formation in the range of 160 to $460 \mathrm{~K}$. The angular distribution of each is different. The distribution becomes sharper as the density of the coadlayer is increased, and it shows the dependence on the crystal azimuth. The correlation between the anisotropic angular distribution and the structure around the reaction site is discussed.
\end{abstract}

\section{INTRODUCTION}

The angular distribution of desorption flux of surface reaction products and the velocity distribution provide dynamic parameters describing the microscopic desorption mechanism. ${ }^{1,2}$ Large deviations from the cosine law and Maxwellian velocity distribution have been reported for the desorption of molecules by several combinative processes, i.e., $\quad 2 \mathrm{H}(a) \rightarrow \mathrm{H}_{2}(g),{ }^{3-12} \mathrm{CO}(a)+\mathrm{O}(a) \rightarrow \mathrm{CO}_{2}(g),,^{13-19}$ $\mathrm{C}(a)+\mathrm{O}(a) \rightarrow \mathrm{CO}(g),{ }^{20,21}$ and $2 \mathrm{~N}(a) \rightarrow \mathrm{N}_{2}(g) .^{22,23}$

The sharp angular distribution has typically been demonstrated by a one-dimensional activation barrier model. ${ }^{1,3,24}$ The one-dimensional treatment was supported by two kinds of observation: (1) the angular distribution of desorbing hydrogen does not show up the crystal symmetry, ${ }^{6,25}$ and (2) the initial sticking probability is increased as a function of the normal component of the incident translational energy in typical activated adsorptions, e.g., $\mathrm{H}_{2}(g) \rightarrow 2 \mathrm{H}(a),{ }^{7.26,27} \quad \mathrm{CH}_{4}(g) \rightarrow \mathrm{CH}_{3}(a)+\mathrm{H}(a),{ }^{28-31}$ $\mathrm{N}_{2}(g) \rightarrow 2 \mathrm{~N}(a),{ }^{32}$ and $\mathrm{CO}_{2}(g) \rightarrow \mathrm{CO}(a)+\mathrm{O}(a){ }^{33}$

The velocity distribution is more sensitive to the features of the model. A two-height barrier model, proposed by Comsa et al., ${ }^{9}$ was an improvement on the above model which failed to describe the velocity distribution of desorbing hydrogen from $\mathrm{Ni}$ (poly) and $\mathrm{Ni}(111),{ }^{8-10}$ or $\mathrm{Cu}(100)$ and $\mathrm{Cu}(111) .{ }^{11}$ However, this model does not account for the fact that the mean translational energy at large desorption angles is much less than that in a Maxwellian distribution at the surface temperature. ${ }^{10}$ Toya and Ohno have successfully explained this slow desorption, considering the restricted motion of the activated molecules parallel to the surface plane. ${ }^{34,35}$ Their model would predict anisotropic angular distributions.

We have previously reported ${ }^{18,19}$ that the angular distribution of the desorption flux of $\mathrm{CO}_{2}$ produced on $\mathrm{Pt}(111)$, $\operatorname{Pd}(111)$, and $\mathrm{Rh}(111)$ becomes sharp as the density of adsorbates surrounding the reaction site is increased. Such sharp distributions were suggested to be caused by severe restriction of motion parallel to the surface plane, as well as the repulsive force exerted on nascent $\mathrm{CO}_{2}$ by the surface. This consideration led to the idea that the anisotropic angular distribution of the flux is dependent on the crystal azi-

\footnotetext{
a) Present address: Institute for Molecular Science, Myodaiji, Okazaki 444, Japan.
}

muth. This azimuth dependence would yield information on the structure around the reaction site through the reaction itself.

This paper reports on the azimuth dependence of the angular distribution of $\mathrm{CO}_{2}$ produced on $\mathrm{Pd}(110)$ surfaces, and discusses the correlation between the azimuth dependence and the structure around reaction sites. An angle-resolved thermal desorption technique was used in this work and the desorption flux distribution was examined over a wide range of coverage.

\section{EXPERIMENTAL}

The experimental apparatus and procedures were essentially the same as those reported previously. ${ }^{17,19}$ The apparatus consisted of a reaction chamber, an analyzer chamber, and a collimator between them. The flux of $\mathrm{CO}_{2}$ molecules passing through the collimator slits, by way of the sample surface, was the largest contributor to the signal of the mass spectrometer in the analyzer chamber (angle-resolved spectra). The desorption was simultaneously recorded by another mass spectrometer in the reaction chamber (angleintegrated spectra).

Two sample holders were used. The first was for angular distribution measurements. It allowed rotation of the crystal azimuth $\phi$. It was set on an axis perpendicular to the collimator axis, and rotated to change the desorption angle (polar angle $\theta$ ). This holder obscured fractional order spots on the LEED screen and the minimum possible temperature of a sample mounted on it was around $170 \mathrm{~K}$. The second holder was used for LEED and general kinetic studies. With this holder, only the desorption angle was variable and it was possible to cool the sample to $100 \mathrm{~K}$.

The crystal was a disk-shaped slice $(10 \mathrm{~mm}$ diameter $\times 0.9 \mathrm{~mm}$ thickness). It was cut from a rod supplied by Metal Crystal LTD. U. K. Both faces were polished with standard metallographic techniques. The sample was mounted on either of the holders via spot-welding it to the Ta wires used to heat the crystal. It was cleaned by prolonged $\mathrm{Ar}^{+}$ bombardment in the temperature range of 300 to $1200 \mathrm{~K}$, and heated in $1 \times 10^{-8}$ Torr oxygen to around $800 \mathrm{~K}$. After the crystal was flashed in vacuo up to $1370 \mathrm{~K}$, no impurity was detected with AES. AES is insensitive to carbon on Pd, since the signal is overlapped by that of the substrate. Therefore, the sample was further exposed to oxygen at room tem- 
perature and heated to remove trace surface carbon which would desorb as $\mathrm{CO}$. This procedure was repeated until no further $\mathrm{CO}$ was formed. The LEED pattern showed a sharp $(1 \times 1)$ structure at this stage. The spot intensity was monitored by a spot photometer with a photomultiplier tube. The temperature was monitored using a chromel-alumel thermocouple spot-welded to the side of the crystal.

In the thermal desorption experiments the sample covered by ${ }^{18} \mathrm{O}$ and $\mathrm{C}^{16} \mathrm{O}$ was resistively heated, while the desorbed $\mathrm{C}^{16} \mathrm{O}^{18} \mathrm{O}$ produced was recorded in both angle-resolved and angle-integrated form. The absolute value of the signal intensity in the two forms cannot be compared as the amplifier systems of the mass spectrometers were different. The use of ${ }^{18} \mathrm{O}_{2}$ improved the signal-to-noise ratio of the mass spectrometer in the analyzer chamber. Neither $\mathrm{C}^{16} \mathrm{O}_{2}$ nor $\mathrm{C}^{18} \mathrm{O}_{2}$ was produced. Oxygen 18 will be designated simply as $\mathrm{O}$ in the following.

\section{RESULTS}

\section{A. Adsorption of $\mathrm{CO}$ and oxygen}

Carbon monoxide forms a $c(2 \times 2)$ structure at a coverage $\left(\theta_{\mathrm{CO}}\right)$ of 0.5 . Further adsorption leads to the formation of a $(4 \times 2)$ structure at $\theta_{\mathrm{CO}}=0.75$. $^{36}$ The exposure required to maximize the spot intensity of both LEED structures was $0.9 \mathrm{~L}\left(1 \mathrm{~L}=1 \times 10^{-6}\right.$ Torr s) and $1.4 \mathrm{~L}$ below room temperature. The relative coverage determined by thermal desorption was normalized at these exposures. The initial sticking probability was estimated to be close to unity below $300 \mathrm{~K} .{ }^{36}$ The desorption at small coverages shows a single peak at $510 \mathrm{~K}$. The peak became broad above $\theta_{\mathrm{CO}}=0.5$ with increasing $\theta_{\mathrm{CO}}$. The desorption occurs at temperatures higher than the oxidation.

Oxygen adsorbs dissociatively and molecularly around $100 \mathrm{~K} \cdot{ }^{37-39}$ The desorption and dissociation of admolecules is complete below $200 \mathrm{~K} .{ }^{40}$ The adatoms form $(2 \times 3)-1 \mathrm{D}^{37}$ [or pseudo- $(1 \times 3)^{38}$ ] and then $c(2 \times 4)$ lattice with the increasing coverage. ${ }^{41,42}$ The complete $c(2 \times 4)$ has a coverage $\left(\theta_{\mathrm{o}}\right)$ of $0.5 .{ }^{43}$ Both structures appear after annealing the oxygen-covered surfaces above $400 \mathrm{~K}$. The coverage was calculated from the thermal desorption peak area. The desorption due to the combination of adatoms peaks above $800 \mathrm{~K}$. The peak area increased linearly with $\mathrm{O}_{2}$ exposure and reached a steady value above $0.8 \mathrm{~L}$. At this stage, a sharp $c(2 \times 4)$ pattern was observed after the annealing. Thus the desorption peak area from this stage was normalized to $\theta_{\mathrm{o}}=0.5$. The initial sticking probability is close to unity below room temperature.

Another LEED pattern appears in the course of the temperature rise. The super structure spots were observed at $( \pm 1 / 2, \pm 5 / 6)$ and $(0, \pm 1 / 2)$ with an accelerating voltage $\left(E_{0}\right)$ of $42 \mathrm{eV}$. This structure is tentatively designated $c(2 \times 6) \cdot{ }^{37,44}$ It appeared from small coverages to saturation. The spots were observed after heating in the range of $200-$ $350 \mathrm{~K}$

\section{B. Coadsorption of oxygen and CO}

$\mathrm{CO}$ adsorbs rapidly on oxygen-covered surfaces. No new LEED patterns were found on the resultant surfaces.
The oxygen LEED pattern was accompanied with high background. Separate domains of $\mathrm{CO}$ and oxygen were confirmed only for small oxygen coverages. No compressed oxygen lattice was found on the present surface. ${ }^{19}$

The spot intensity of the oxygen lattices was monitored by a spot photometer during subsequent heating. Typical results of $c(2 \times 4)$ are shown in Fig. 1. The intensity [curve (a) ] increased sharply around $T_{P}=400 \mathrm{~K}$, when the oxygen-covered surface was heated to a desired temperature, $T_{P}$. The intensity was measured at $190 \mathrm{~K}$, because it maintained an almost steady value below this temperature. The surface exhibited a stable $c(2 \times 4)-\mathrm{O}$ structure above $T_{P}=500 \mathrm{~K}$, as shown in the figure.

The spot intensity was largely attenuated after CO exposure at $110 \mathrm{~K}$ [Fig. 1 curves (c) and (d)]. The surface was again heated and the spot intensity was measured at $190 \mathrm{~K}$. The intensity was mostly recovered in the range of $T_{P}=350-400 \mathrm{~K}$ for small $\mathrm{CO}$ exposures [curve (c)]. It decreased rapidly above $T_{P}=400 \mathrm{~K}$. The spot showed a streak structure in the [001] direction and further split into the $(2 \times 3)-1 D$ position. The spot intensity began to decrease at lower temperatures for large $\mathrm{CO}$ exposures [curve (d)]. As shown in Sec. III C, these decreases are due to the removal of $\mathrm{O}(\mathrm{a})$ by the reaction with $\mathrm{CO}$.

The spot intensity varied in a similar way when the surface, precovered by oxygen, was annealed to only $200 \mathrm{~K}$, exposed to $\mathrm{CO}$ and then heated [curve (b)]. It decreased rapidly around $T_{P}=400 \mathrm{~K}$. Above this a streak structure in the [001] direction appeared. Below $T_{P}=400 \mathrm{~K}$ the intensity followed nearly the same curve as that without $\mathrm{CO}$ exposure. This means that oxygen orders in $c(2 \times 4)$ and/or $(2 \times 3)-1 \mathrm{D}$ lattices, just as it would without $\mathrm{CO}$ exposure.

The change in the spot intensity of the $(2 \times 3)-1 D$ structure, due to increasing heat treatment temperature, was similar to that of $c(2 \times 4)$. The $(2 \times 3)-1 \mathrm{D}$ structure was observed at oxygen exposures of $0.2-0.3 \mathrm{~L}$ followed by heating above $400 \mathrm{~K}$. The intensity was maximum around $T_{P}=330$ $\mathrm{K}$, during heating, after a $\mathrm{CO}$ exposure of $0.3 \mathrm{~L}$. The occurrence of the maximum intensity shifted to $T_{P}=370 \mathrm{~K}$ when the oxygen-covered surface was heated to only $200 \mathrm{~K}$ before $\mathrm{CO}$ exposure. This indicates that the reactivity of oxygen adatoms towards $\mathrm{CO}$ is altered by the heat treatment.

The spot intensity of the $c(2 \times 6)$ structure was much less than the others. Additional decay caused by $\mathrm{CO}$ was hardly detected. The maximum intensity was observed around $T_{P}=300 \mathrm{~K}$, irrespective of $\mathrm{CO}$ exposure.

We have concluded that the surface is covered by either of stable oxygen lattices, i.e., $c(2 \times 4)-\mathrm{O},(2 \times 3)-1 \mathrm{D}-\mathrm{O}$ or the intermediate structures, during the $\mathrm{CO}_{2}$ formation above $400 \mathrm{~K}$. Below this temperature, the oxygen lattice remains, during the removal of oxygen, as it was before $\mathrm{CO}$ exposure (heat-treated oxygen lattices), or changes in a way similar to that without $\mathrm{CO}$ exposure (without preheating).

\section{C. $\mathrm{CO}_{2}$ formation}

The reaction of $\mathrm{O}$ (a) with $\mathrm{CO}$ (a) can take place at 200 $\mathrm{K}$ when the reactant coverages are high. To study the structures at the reaction sites, the coadlayer was prepared by exposing the oxygen-covered surface to $\mathrm{CO}$ at $110 \mathrm{~K}$. The 


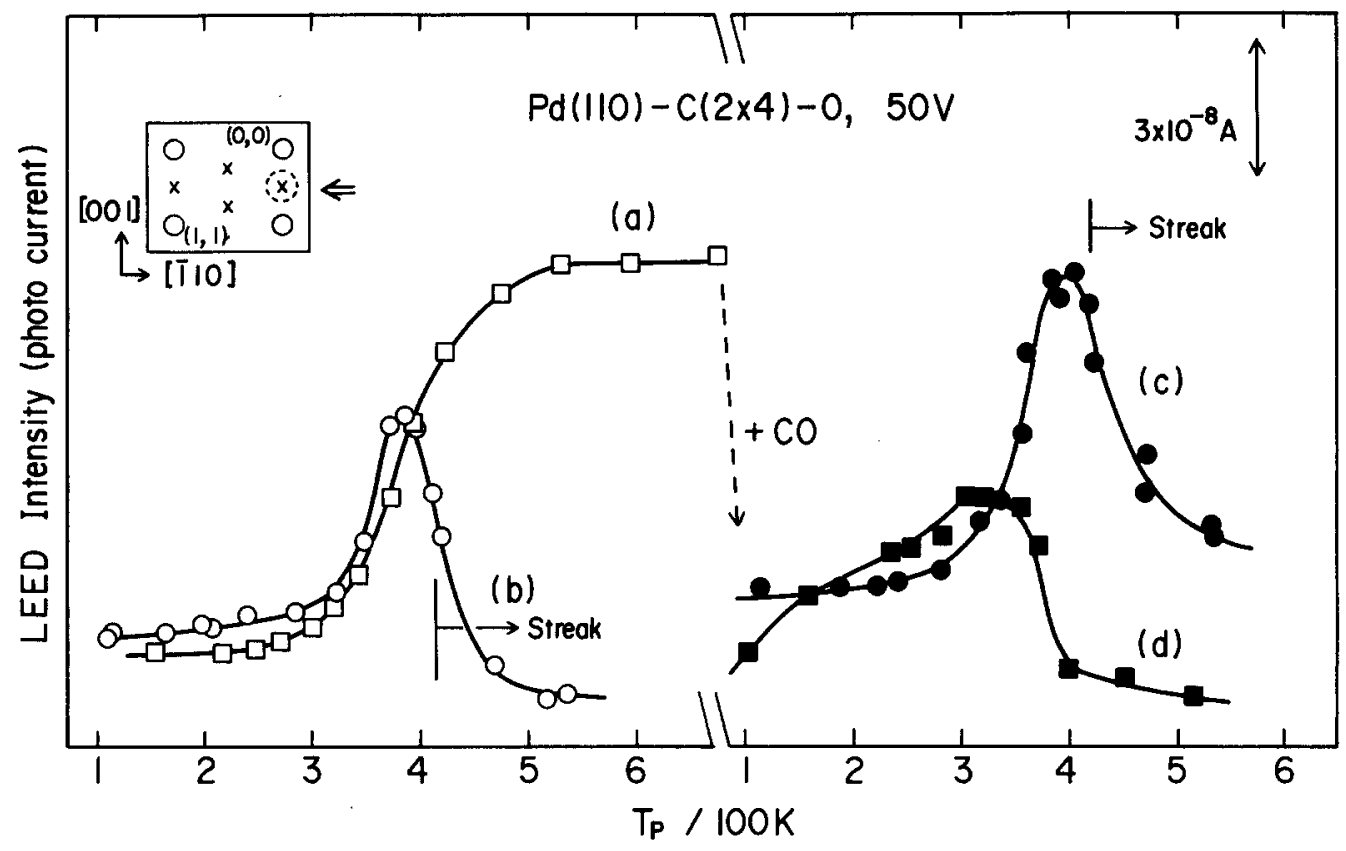

FIG. 1. Variation of the LEED spot intensity due to $c(2 \times 4)-0$. The surface, saturated by oxygen at $110 \mathrm{~K}$, was first heated to 200 K. It was heated to $T_{P}$, after (a) heating as above, (b) exposing to $0.3 \mathrm{~L} \mathrm{CO}$ at $110 \mathrm{~K}$, and heating to $520 \mathrm{~K}$ followed by $\mathrm{CO}$ exposure of $0.3 \mathrm{~L}$ at $110 \mathrm{~K}(\mathrm{c})$ or 1.4 $L(d)$. The intensity of the spot indicated by the arrow in the inserted figure was measured at $190 \mathrm{~K}$. The open circles represent substrate spots and the crosses, super structure spots. No background intensity was subtracted. The vertical bars indicate the beginning of streak structures.

surface exposed to oxygen was preheated to $200 \mathrm{~K}$ to remove oxygen admolecules. The heating of this coadlayer yielded five peaks of $\mathrm{CO}_{2}$ formation; $P_{1}-\mathrm{CO}_{2}$ at $460-430 \mathrm{~K}, P_{2}-\mathrm{CO}_{2}$ at $390-350 \mathrm{~K}, P_{3}-\mathrm{CO}_{2}$ around $320 \mathrm{~K}, P_{4}-\mathrm{CO}_{2}$ at $230-270 \mathrm{~K}$, and $P_{5}-\mathrm{CO}_{2}$ around $160 \mathrm{~K}$. Typical $\mathrm{CO}_{2}$ spectra are reproduced in Fig. 2(a). For $\theta_{\mathrm{o}}$ (initial oxygen coverage) $=0.5$, $P_{2}-\mathrm{CO}_{2}$ appeared first at small $\mathrm{CO}$ exposures. With increasing $\mathrm{CO}$ exposures, $P_{1}-\mathrm{CO}_{2}$ was observed at higher temperatures and became predominant.

At high $\mathrm{CO}$ exposures, $\mathrm{CO}_{2}$ formation was extended to lower temperatures. Even below $200 \mathrm{~K}$, a significant $\mathrm{CO}_{2}$ formation was observed. The $P_{4}$ and $P_{5}$ peaks observed below $300 \mathrm{~K}$ are barely separated. Above $1.3 \mathrm{~L} \mathrm{CO}$, no change was found in the spectra. The $\mathrm{CO}$ exposure of $1.3 \mathrm{~L}$ was enough to remove most of the oxygen at $\theta_{\mathrm{o}}=0.5$. This means that $\mathrm{CO}$ adsorbs quickly on the oxygen-covered surface. The resultant coadlayer has a high density of oxygen and $\mathrm{CO}$. The total coverage is close to unity. A noticeable difference was found in the $\mathrm{CO}_{2}$ spectra when the surface covered by oxygen was heated to $510 \mathrm{~K}$ before $\mathrm{CO}$ exposure, as shown by the dotted curves in Fig. 2(a). $P_{2}$ was suppressed and $P_{3}$ became apparent.

At small oxygen coverages and $\mathrm{CO}$ exposures, a single peak of $P_{1}-\mathrm{CO}_{2}$ first appeared at $460 \mathrm{~K}$. The predominance of $P_{1}$ or $P_{2}$ was dependent on the initial oxygen coverage, as shown in Fig. 3. The $\mathrm{CO}_{2}$ formation was monitored at various oxygen coverages and at a low-level $\mathrm{CO}$ exposure $(0.05$ $\mathrm{L})$. The $\mathrm{CO}_{2}$ spectra were deconvoluted by assuming constant half-widths of $\mathrm{CO}_{2}$ peaks [Fig. 3(a) ]. The peak areas are plotted against $\theta_{\mathrm{o}}$ in Fig. 3(b). The formation of $P_{1}-\mathrm{CO}_{2}$ was rapidly suppressed above $\theta_{\mathrm{o}}=0.25$. At higher values of $\theta_{0}, P_{2}-\mathrm{CO}_{2}$ was predominant. These peaks are not differentiated by the oxygen coverage only. The separation of $P_{1}$ from $P_{2}$ became unclear when the oxygen-covered surface was heated to $510 \mathrm{~K}$ before $\mathrm{CO}$ exposure. In this case, with increasing $\theta_{0}$, the $P_{1}-\mathrm{CO}_{2}$ peak shifted to the temperature range of the $P_{2}-\mathrm{CO}_{2}$ peak. The latter was suppressed signifi-

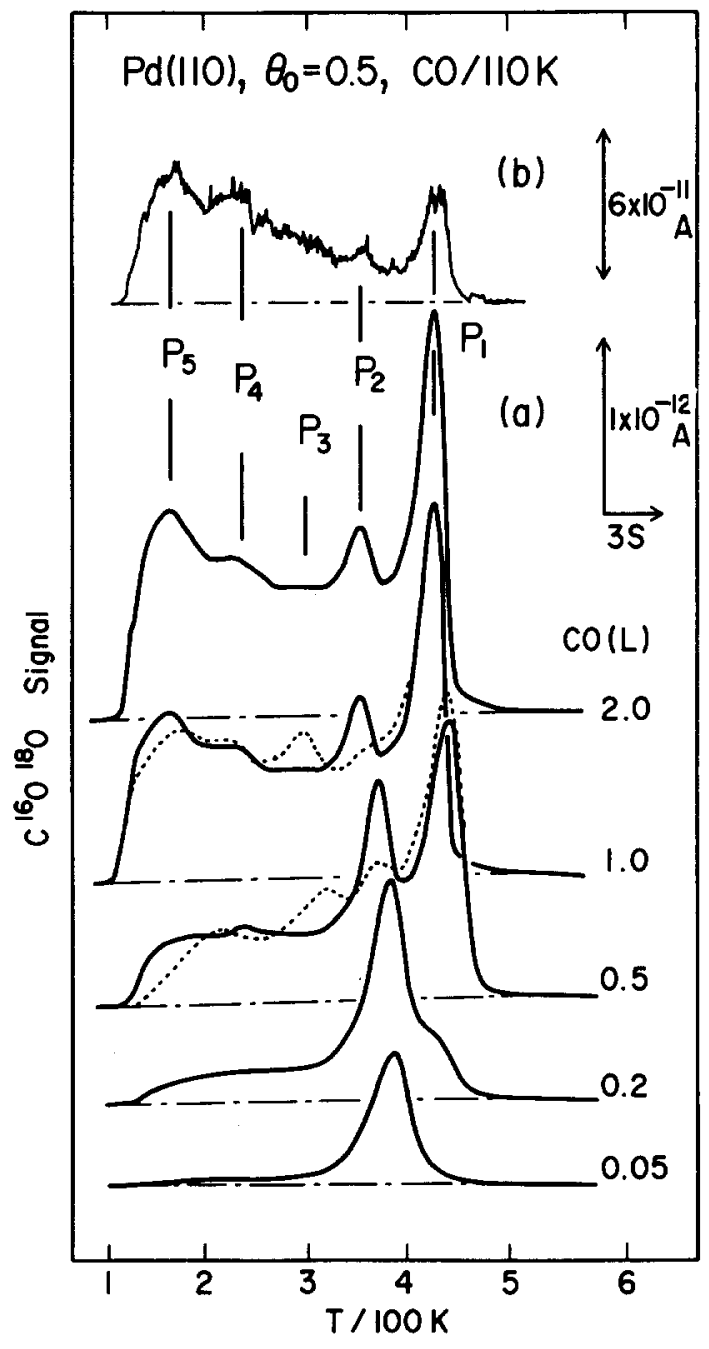

FIG. 2. $\mathrm{CO}_{2}$ spectra generated at high oxygen coverage and various $\mathrm{CO}$ exposures. The spectra were simultaneously recorded in both (a) angle-integrated and (b) angle-resolved form. The latter was for $2.0 \mathrm{~L} \mathrm{CO}$ and in the normal direction. The surface saturated by oxygen was first heated to $200 \mathrm{~K}$ and exposed to $\mathrm{CO}$ at $110 \mathrm{~K}$. The dotted curves represent spectra when the oxygen-covered surface was heated to $510 \mathrm{~K}$. 

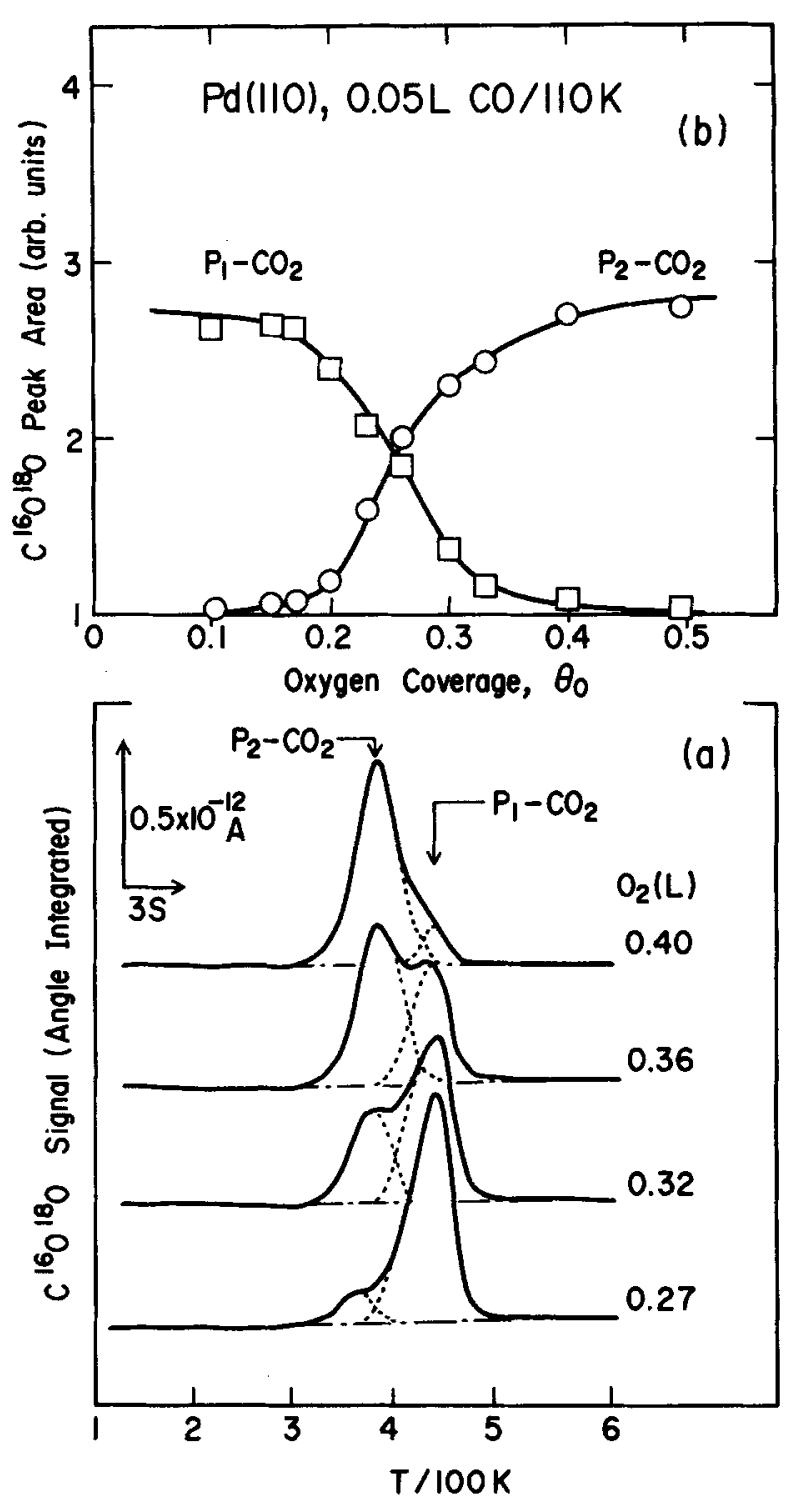

FIG. 3. (a) $\mathrm{CO}_{2}$ formation spectra in angle-integrated form at various oxygen preexposures and $0.05 \mathrm{~L} \mathrm{CO}$ exposure. (b) Variation of $\boldsymbol{P}_{1}-$ and $\boldsymbol{P}_{2-}$ $\mathrm{CO}_{2}$ peak areas with the initial oxygen coverage.

cantly. The difference between them is caused by the state of oxygen as well as the oxygen coverage. This is also seen in Fig. 2(a).

The differentiation of each $\mathrm{CO}_{2}$ peak became clear when the coadlayer was prepared at $200 \mathrm{~K}$. At this temperature, the reaction occurred slowly. The results are summarized in Fig. 4(a). $P_{1}$ and $P_{2}$ were predominant for small $\mathrm{CO}$ exposures. The appearance of $P_{2}-P_{4}$ was delayed in higher $\mathrm{CO}$ exposures, when $\theta_{\mathrm{o}}$ was small. With high $\mathrm{CO}$ exposures, $P_{3}$ and $P_{4}$ grew, and $P_{1}$ and $P_{2}$ were attenuated.

The right panel of the figure summarizes the $\mathrm{CO}_{2}$ spectra in the angle-resolved form in the normal direction (desorption angle $\theta=0^{\circ}$ ). The ratio of the peak height in both forms provides a general overview of the angular distribution of the $\mathrm{CO}_{2}$ desorption flux. The signals of $P_{3}$ and $P_{4}$ are intense in the normal direction, as compared with the small peaks in the angle-integrated form. On the other hand, the peak heights of $P_{1}$ and $P_{2}$ are comparable in both forms. This

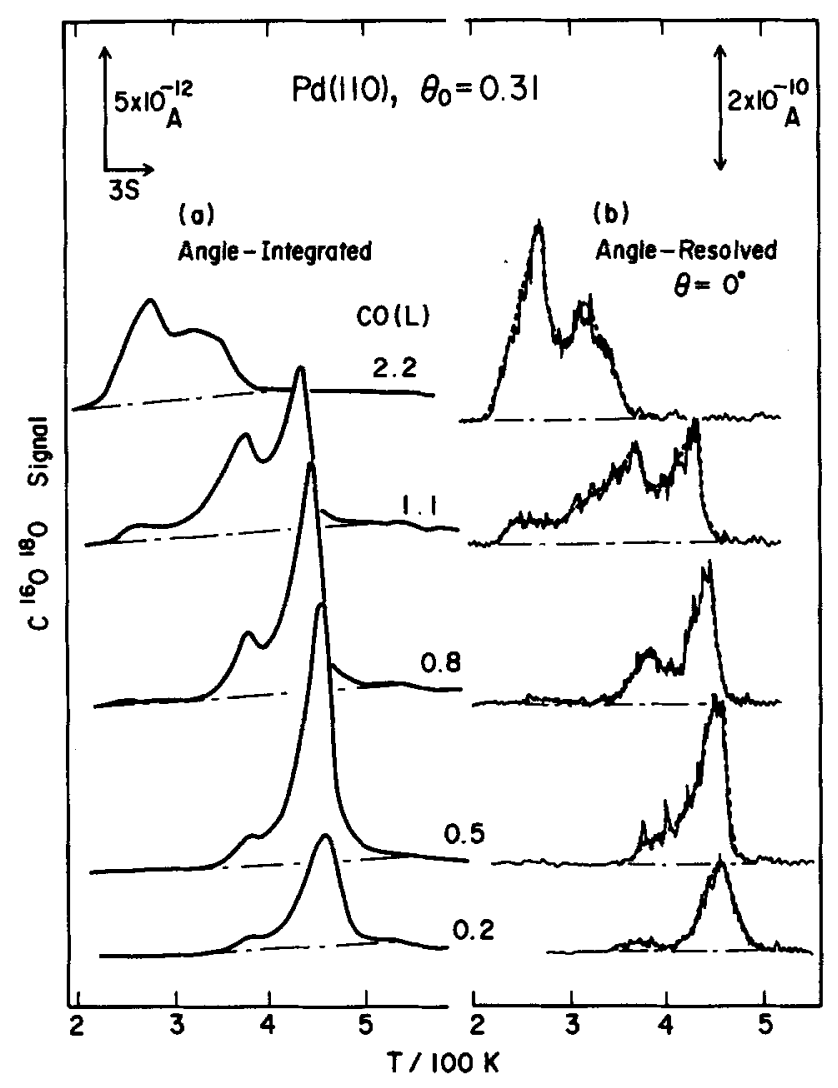

FIG. 4. $\mathrm{CO}_{2}$ spectra generated at medium oxygen coverage and various $\mathrm{CO}$ exposures. The spectra were simultaneously recorded in both (a) angle-integrated and (b) angle-resolved forms. Oxygen and then $\mathrm{CO}$ were adsorbed at $200 \mathrm{~K}$.

means that the desorption of $P_{3}$ and $P_{4}$ is directed more sharply than that of $P_{1}$ and $P_{2}$. A similar comparison is possible for $P_{5}$ in Figs. 2(a) and 2(b). The signals of $P_{1}$ and $P_{2}$ are high in the angle-integrated form, and those of $P_{4}$ and $P_{5}$ become comparable with them in the angle-resolved form. This means that the $P_{4}$ and $P_{5}$ have sharper angular distributions than $P_{1}$ and $P_{2}$.

The $\mathrm{CO}_{2}$ spectra were simplified when the adsorption sequence was reversed; $\mathrm{CO}$ was dosed first and then $\mathrm{O}_{2}$ was introduced in large amounts. The subsequent thermal desorption induced the formation of $P_{1}-$ and $P_{2}-\mathrm{CO}_{2}$ below $\theta_{\text {Co }}$ (the initial $\mathrm{CO}$ coverage) $=0.15$. Only $P_{1}-\mathrm{CO}_{2}$ was produced in the range of $\theta_{\mathrm{CO}}=0.15-0.35$. No $\mathrm{CO}_{2}$ was formed above $\theta_{\mathrm{CO}}=0.35$. This sequence was not used in the following experiments.

\section{Angular distribution}

The desorption flux of $\mathrm{CO}_{2}$ showed anisotropic angular distributions dependent upon the crystallographic orientation of the surface. The distribution along the trough in the [110] direction is broader than that in the direction perpendicular to it. The distribution in all directions is much sharper than a simple cosine law. Figures 5 and 6 reproduce the angle-integrated $\mathrm{CO}_{2}$ spectra and typical angle-resolved spectra observed at various desorption angles. The desorption angle was varied perpendicular to the trough (along the $[00 \overline{1}]$ direction, the crystal azimuth $\phi=0^{\circ}$ ). The peak temperature remained invariant with increasing $\theta$, whereas the 


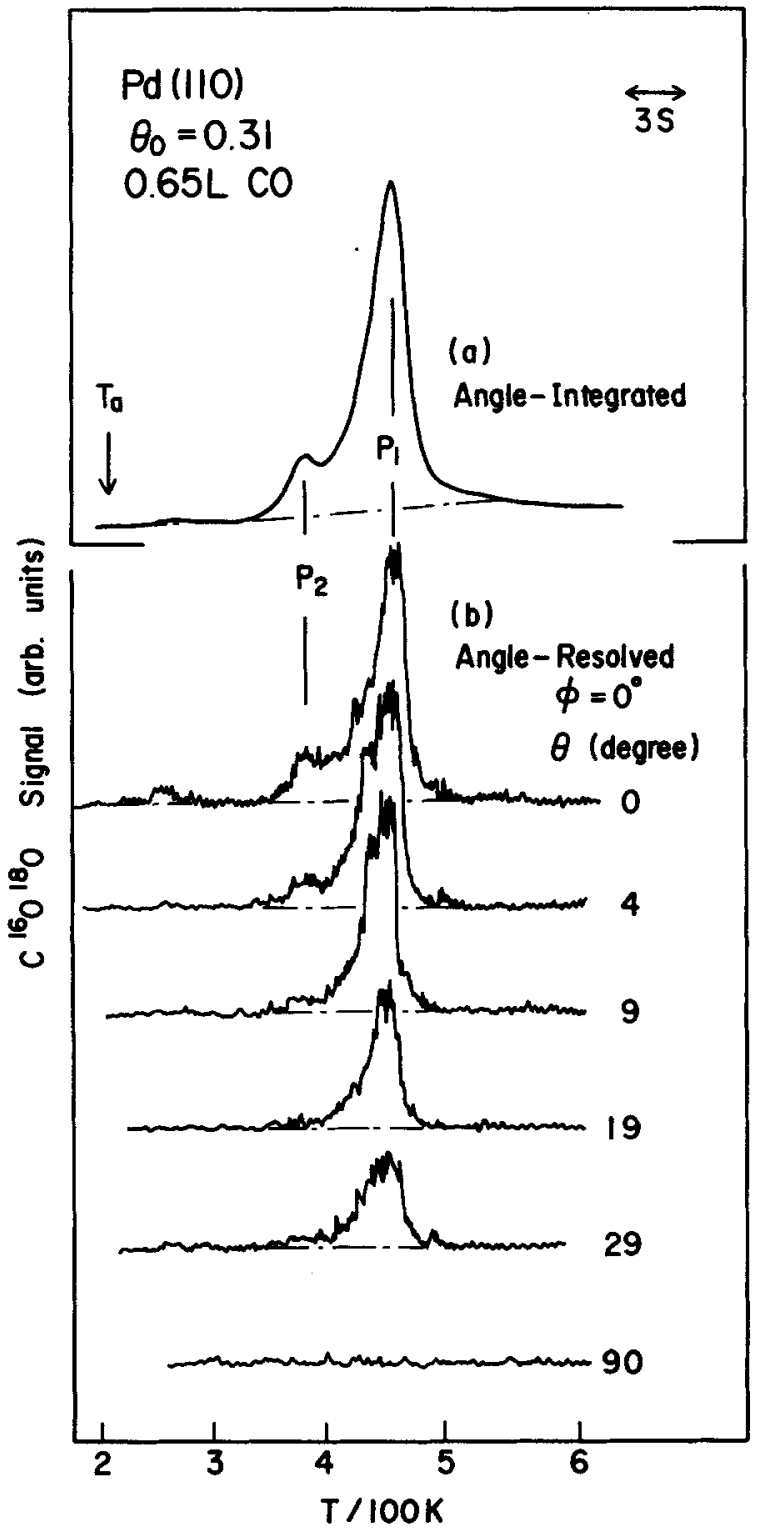

FIG. 5. (a) $\mathrm{A} \mathrm{CO}_{2}$ formation spectrum in angle-integrated form at medium oxygen coverage and $\mathrm{CO}$ exposure. (b) Angle-resolved spectra observed at various desorption angles in the $[00 \overline{1}]$ direction. $T_{a}$ is the adsorption temperature.

peak height decreased rapidly. The peak height of $P_{1}-\mathrm{CO}_{2}$ is plotted against the desorption angle in Fig. 7. Correction was made for that an increasing area of the front sample surface fell inside the solid angle of the collimator apertures, when the crystal was rotated. The variation of peak height was $(\cos \theta)^{10 \pm 2}$. No dependence on the oxygen coverage was found.

The angular distribution of $P_{1}-\mathrm{CO}_{2}$ in the [110] direction $\left(\phi=90^{\circ}\right)$ is shown in Fig. 8. The peak height varied as $(\cos \theta)^{2 \sim 3}$, independent of the oxygen coverage. This is broader than that in the $[00 \overline{1}]$ direction. It is interesting to examine the dependence of the $\mathrm{CO}_{2}$ signal on the crystal azimuth at a fixed desorption angle. The results at $\theta=25^{\circ}$ are summarized in Fig. $9(\mathrm{a})$. The $P_{1}-\mathrm{CO}_{2}$ signal varied smoothly between $\phi=0^{\circ}$ and $90^{\circ}$. It showed a minimum at $\phi=0^{\circ}$ and a maximum at $\phi=90^{\circ}$, as expected from above angular distributions.

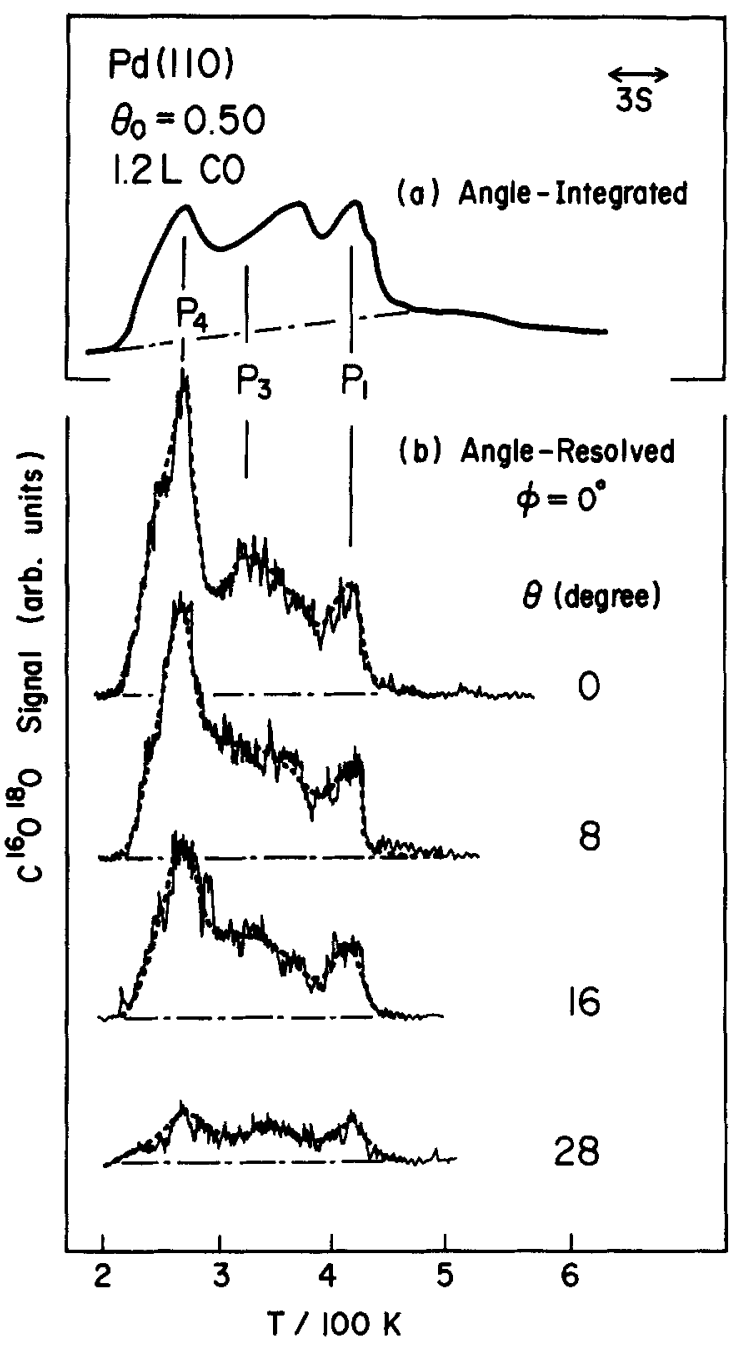

FIG. 6. (a) $\mathrm{A} \mathrm{CO}_{2}$ formation spectrum in angle-integrated form at high oxygen coverage and $\mathrm{CO}$ exposure. (b) Angle-resolved $\mathrm{CO}_{2}$ spectra observed at various desorption angles in the $[00 \overline{1}]$ direction. The adsorption was at $200 \mathrm{~K}$.

The angular distribution of $P_{4}-\mathrm{CO}_{2}$ was determined at high oxygen coverages. Typical angle-resolved spectra at various desorption angles are reproduced in Fig. 6(b). A large difference in the angular distribution between $P_{1}$ and $P_{4}$ can be noted from comparison of an angle-integrated spectrum in the upper panel with those at $\theta=0^{\circ}$ in angleresolved form in the lower panel. The angle-resolved signal of $\boldsymbol{P}_{4}$ decreased rapidly with increasing $\theta$ and the ratio of $\boldsymbol{P}_{4}$ to $P_{1}$ also decreased. This means again that the angular distribution of $P_{4}$ is sharper than that of $P_{1}$. No $P_{2}-\mathrm{CO}_{2}$ peak was seen in the angle-resolved form, whereas the peak was clearly apparent in the angle-integrated form. The peak of $P_{3}$ is just the opposite. This indicates that the direction of desorption of $P_{3}$ is more normal to the surface than that of $P_{2}$. The angular distribution of $P_{4}-\mathrm{CO}_{2}$ at $\phi=0^{\circ}$ is represented in Fig. 10, and that at $\phi=90^{\circ}$ in Fig. 11. The variation of peak height was $(\cos \theta)^{20 \pm 5}$ at $\phi=0^{\circ}$, whereas it was $(\cos \theta)^{13 \pm 2}$ at $\phi=90^{\circ}$. This difference is apparent but not significant. The crystal azimuth dependence of $P_{4}-\mathrm{CO}_{2}$ at $\theta=15^{\circ}$ is shown in Fig. 9(b). The azimuthal dependence is much less than that for $P_{1}-\mathrm{CO}_{2}$. 


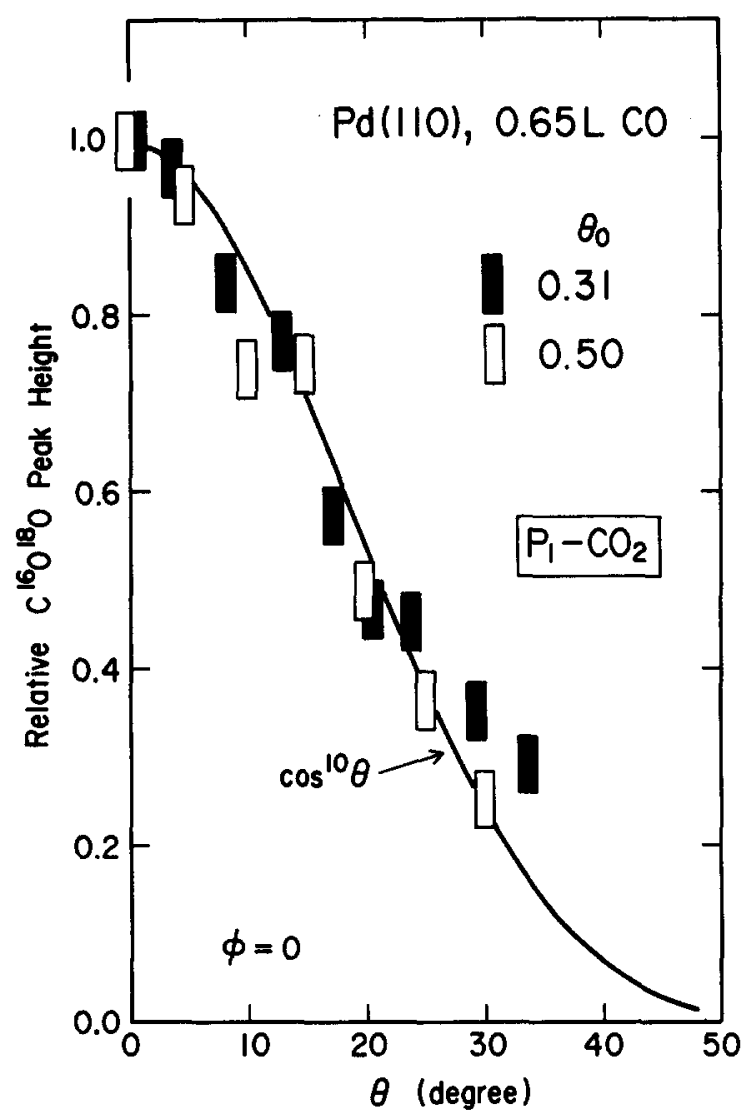

FIG. 7. Angular distribution of the desorption flux of $P_{1}-\mathrm{CO}_{2}$ in the $[00 \overline{1}]$ direction. Two series at different $\theta_{\mathrm{o}}$ are summarized. Experimental details are given in Fig. 5.

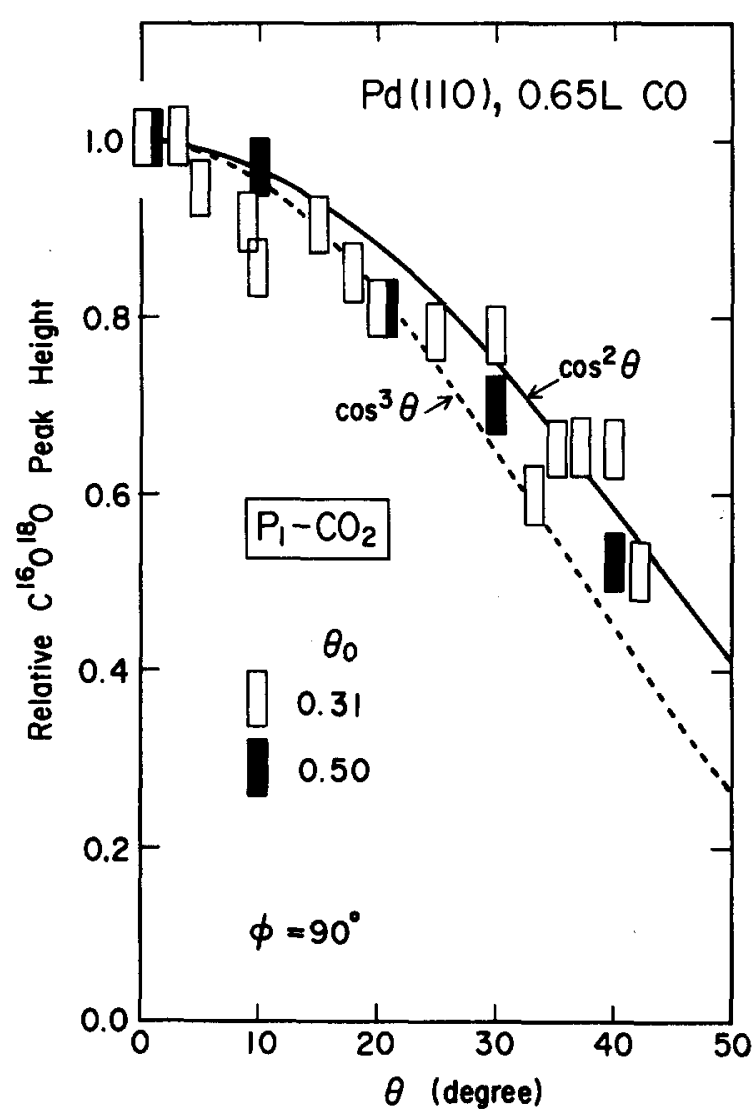

FIG. 8. Angular distribution of the $P_{1}-\mathrm{CO}_{2}$ desorption flux along the [110] direction. Series at different $\theta_{\mathrm{o}}$ are summarized.

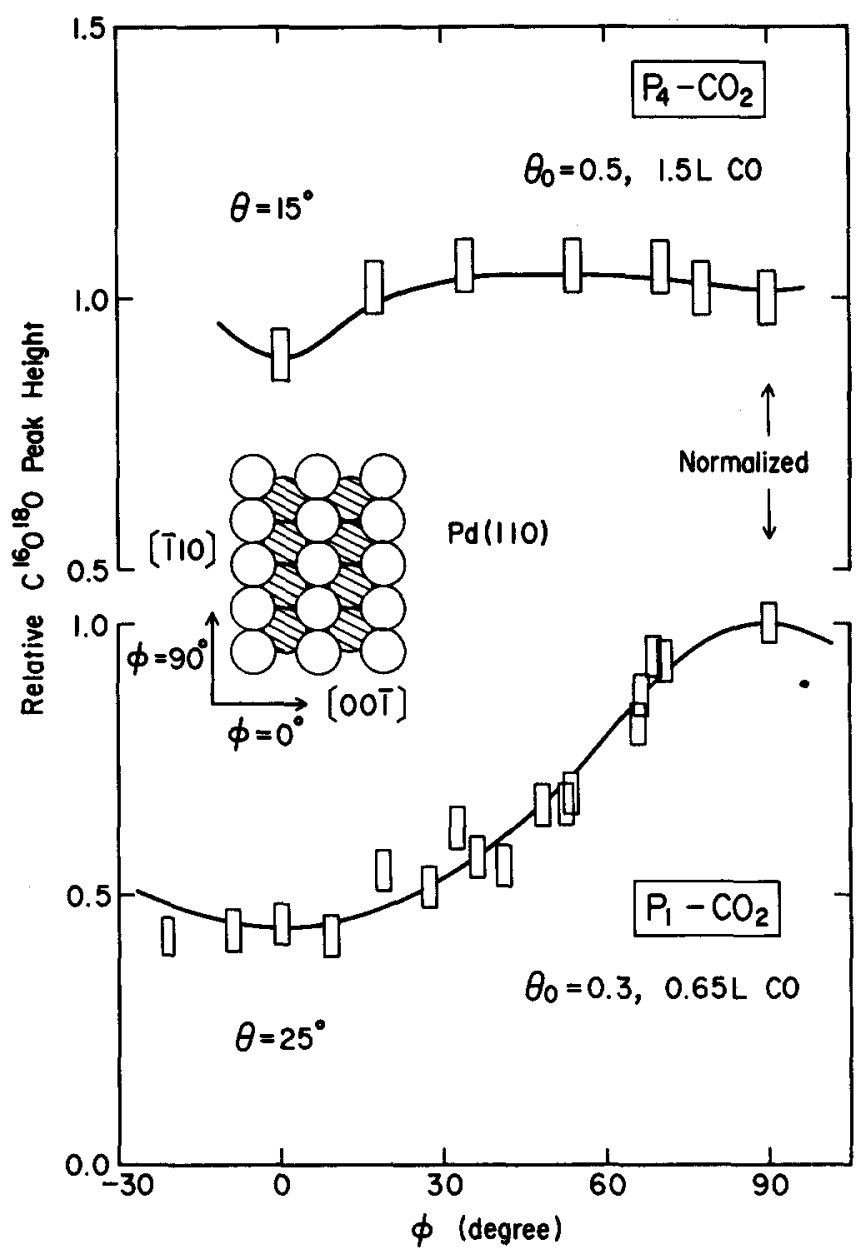

FIG. 9. Crystal azimuth dependence of the desorption flux of (a) $P_{1}-$ and (b) $P_{4}-\mathrm{CO}_{2}$ at fixed desorption angles. The signal intensity was normalized to the value at $\phi=90^{\circ}$. Experimental conditions are given in the figure. The crystal azimuth is defined in the inserted figure.

The angular distribution of $P_{2}-\mathrm{CO}_{2}$ desorption varied as $(\cos \theta)^{12 \pm 2}$ at $\phi=0^{\circ}$. This $\mathrm{CO}_{2}$ shows a crystal azimuth dependence similar to that of $P_{1}-\mathrm{CO}_{2}$. The angular distribution of $P_{3}-\mathrm{CO}_{2}$ desorption was not successfully determined as the peak was overlapped by the tail of the $P_{4}$ peak. $P_{5}-\mathrm{CO}_{2}$ was expected to show the sharpest angular distribution, as discussed above, but the angular distribution has not been determined at this time.

\section{DISCUSSION}

\section{A. Overview of a desorption model}

The desorption flux of molecules, which are completely thermalized on the surface, obeys the cosine law. Several desorption systems indicate nonequilibrium distributions of the flux. The desorption is directed normal to the surface. Such surface processes are characteristic of combinative desorption..$^{3-23}$ The reverse process (dissociative adsorption) has a fairly large activation energy. ${ }^{7,26-33}$ This energy barrier originates from a repulsive force operative between surfaces and molecules. The physical molecular adsorption generally occurs further from the surface than the chemical adsorption of dissociated fragments. The surface is likely to exert a repulsive force on molecules produced associatively. 


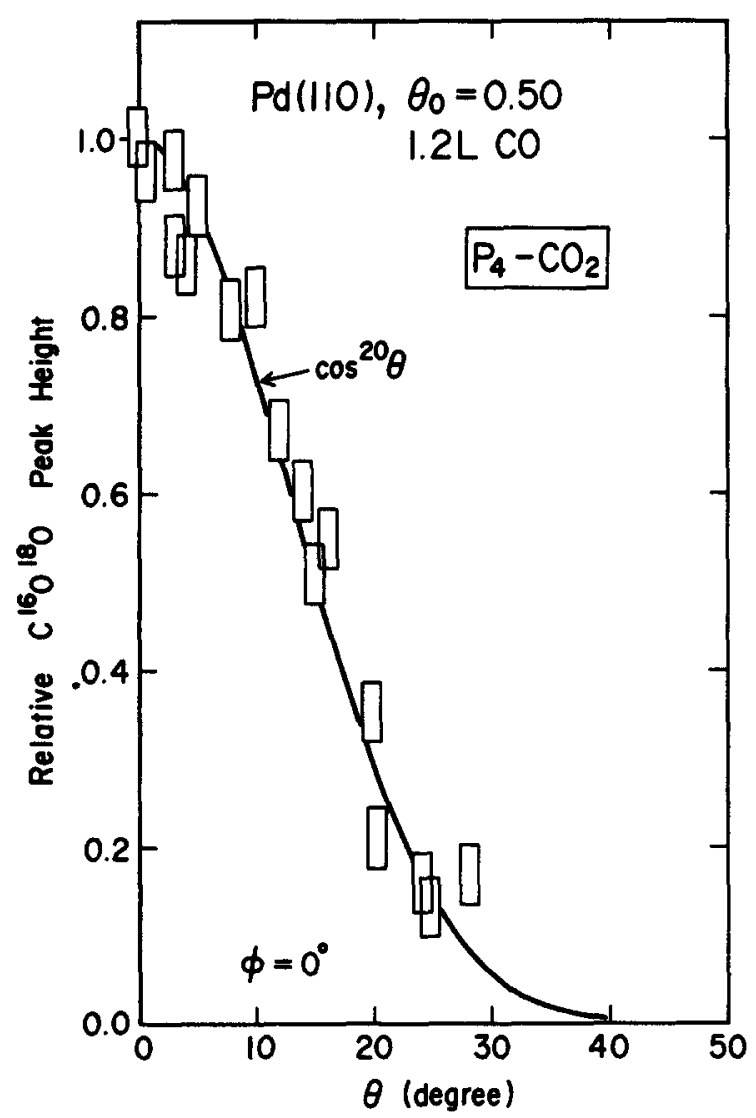

FIG. 10. Angular distribution of $P_{4}-\mathrm{CO}_{2}$ desorption in the [001] direction.

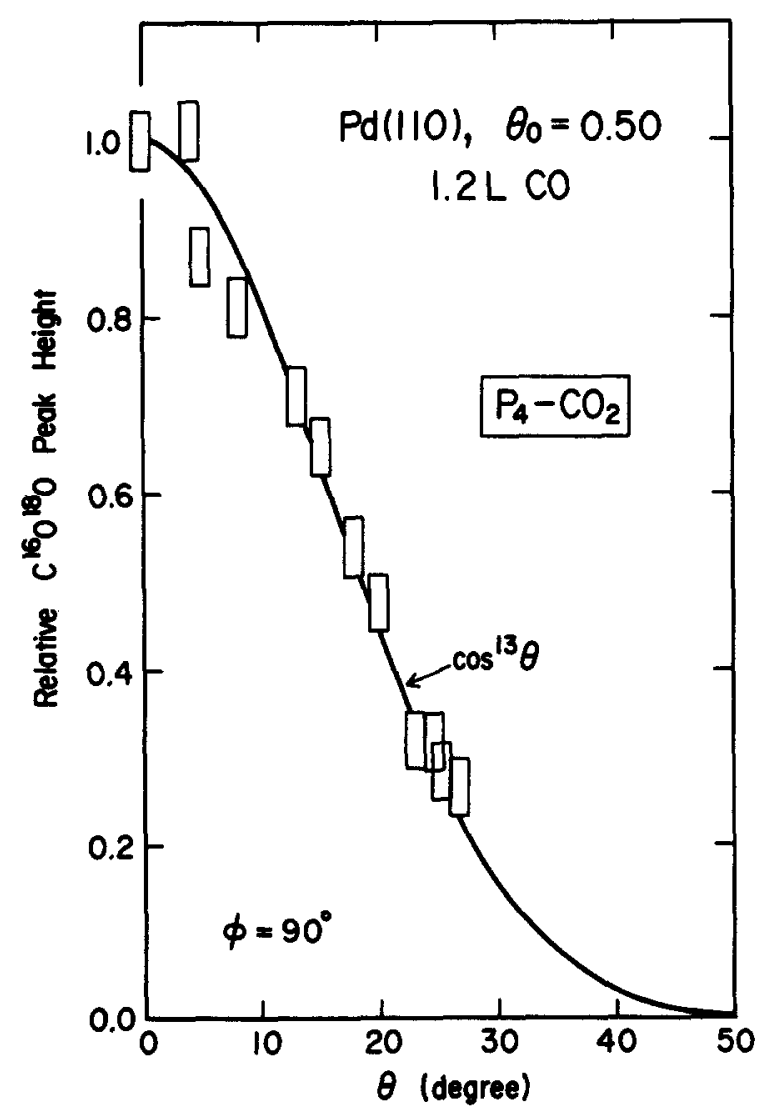

FIG. 11. Angular distribution of $P_{4}-\mathrm{CO}_{2}$ desorption along the $[\overline{1} 10]$ direction.
The desorption flux has been discussed along this line as a function of desorption angle by Comsa ${ }^{24}$ and van Willigen. ${ }^{3}$ They proposed a one-dimensional activation barrier model. The angular distribution of desorption flux is, in general, determined by the ratio of the velocity component normal to the surface to that parallel to the surface plane. Both components may have their own distributions. The normal component may be represented by the above one-dimensional activation barrier model. The higher the barrier is, the higher the values of the normal component, and the sharper the angular distribution yielded. In this model, the motion of molecules immediately prior to desorption, "the activated complex," is free in all directions parallel to the surface plane. The parallel velocity component can be described by a Maxwellian distribution at the surface temperature. No anisotropic angular distribution is predicted in this model.

Goodman presented an interesting model in a different way, ${ }^{45}$ in which the velocity distribution was, a priori, assumed to be anisotropic, depending on the desorption angle. The physical basis for the anisotropy can be found in a new model proposed by Toya and Ohno. ${ }^{34,35}$ They have introduced restricted motion of the activated complex (vibration of the center of mass of the activated complex, parallel to the surface plane) around reaction sites, into the activation barrier model. In their model the vibrational motion of the activated complex is converted into the translational motion of desorbed molecules, which contributes most to the velocity at large desorption angles. This model is helpful in discussion of the anisotropic angular distribution in the present work. The momentum of vibration at the ground state is distributed around zero [Fig. 12(d)]. It becomes high and broad at higher excitation levels [Fig. 12(c)]. The sharp angular distribution is expected when the potential energy curve for the vibration is steep, and the activated complex is vibrated mostly at the ground state. On the other hand the distribution becomes broad when the potential curve is shallow and the vibrational motion is excited to higher levels. The total momentum parallel to the surface plane should increase in this case. Such an anisotropic potential energy surface is expected for the CO oxidation on $\mathrm{Pd}(110)$ surfaces.

\section{B. CO oxidation on Pd(110)}

We consider first the position of the activated complex. A detailed discussion of the $\mathrm{CO}_{2}$ formation site has previously been given for the same reaction on $\operatorname{Pd}(111)$ surfaces. ${ }^{19} \mathrm{~A}$ similar situation is expected on Pd(110) surfaces. Nishijima et al. have proposed, through analysis of a single $\mathrm{Pd}-\mathrm{O}$ vibrational mode by electron energy loss spectroscopy measurements, ${ }^{37}$ that oxygen adatoms are located on long-bridge sites in the trough [Fig. 12(a)-(LB)]. No intensity-voltage character of LEED has been reported yet. This position has been proposed for oxygen on $\mathrm{Cu}(110)^{46}$ and $\mathrm{Ag}(110) .^{47,48}$

$\mathrm{CO}$ molecules are more mobile than oxygen adatoms. They are likely to diffuse to oxygen in the trough and react with it, producing $\mathrm{CO}_{2}$. The location of $\mathrm{CO}_{2}$ formation is illustrated in Fig. 12(b). This structure is sketched by considering the bond distance between $\mathrm{O}(\mathrm{a})$ and metal atoms on $\mathrm{Pd}(111)$. The size of $\mathrm{CO}_{2}$ physisorbed is derived from 


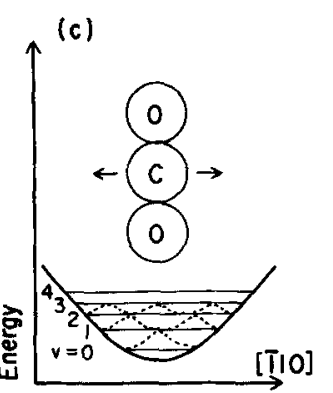

(b)

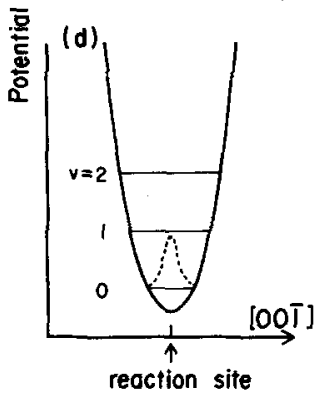

(0)

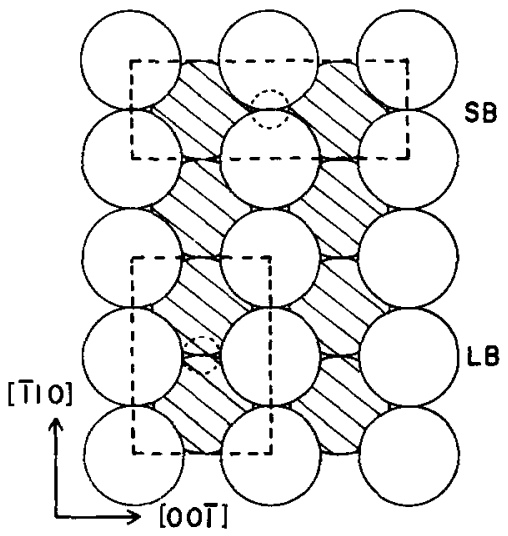

FIG. 12. (a) Unit cells and sites for $P_{1}-\mathrm{CO}_{2}$ formation. Dotted circles represent oxygen adatoms. (b) Sketches of sections of a long bridge site for $\mathrm{CO}_{2}$ formation. A dotted curve is drawn using van der Waals' radii. (c) and (d) Schematic potential curves for the motion of $\mathrm{CO}_{2}$, immediately prior to the desorption, in two directions. Dotted curves represent a momentum distribution at each vibrational level, $v$.

van der Waals' radii. The equilibrium position was estimated to be about $3.3 \AA$ from the surface. The product will be pushed out into vacuum during the formation.

$P_{1}-\mathrm{CO}_{2}$ is formed in the coadlayer with small coverages as shown in Fig. 3. The interaction between the forming $\mathrm{CO}_{2}$ and the surrounding adspecies may be ignored. The motion of desorbing $P_{1}-\mathrm{CO}_{2}$ is mostly affected by palladium atoms. It may be restricted severely in the [001] direction. The trough around the oxygen on a LB site is steep in the $[00 \overline{1}]$ direction, and fairly flat in the $[\overline{1} 10]$ direction. According to the discussion in the previous section, the angular distribution is expected to be sharp in the $[00 \overline{1}]$ direction and to become broad in the [110] direction. This was actually observed. The situation of $P_{2}-\mathrm{CO}_{2}$ is similar to that of $P_{1}$, since the adspecies density is close to that for $P_{1}-\mathrm{CO}_{2}$ formation.

This model predicts that the mean velocity of desorbing $\mathrm{CO}_{2}$ at large desorption angles in the [001] direction is less than that in the [110] direction. Measurements of velocity along this line are now underway.

A different anisotropy of the angular distribution was expected when oxygen adatoms are located on short bridge sites [SB in Fig. 12(a)]. It was thought that the activated complex would move smoothly in the [00 $\overline{1}]$ direction, since a space is open. This prediction, however, was not confirmed.

The small anisotropy of $P_{4}-\mathrm{CO}_{2}$ desorption was observed. As discussed in Sec. III C, the surface was covered by a dense coadlayer during $P_{4}-\mathrm{CO}_{2}$ formation. Oxygen ada- toms are closely surrounded by $\mathrm{CO}$. The parallel motion of forming $\mathrm{CO}_{2}$ may be severely restricted in all directions. The angular distribution is expected to be sharp and the anisotropy to become less. ${ }^{19}$

\section{Dynamic approach to reaction sites}

The azimuthal dependence of the desorption flux of hydrogen has been examined on $\mathrm{Cu}(111),(110),(100),{ }^{6}$ and $\mathrm{Ni}(111),(110)^{25}$ surfaces. However, no dependence was found. Balooch et al. argued that the equipotential lines for the repulsive portion of $\mathrm{H}_{2}$ are approximately parallel to the surface plane at a distance farther from the surface than the position for activated complex formation. ${ }^{6}$

We have considered two additional factors for why the anisotropy in the angular distribution becomes obscure. The first is high occurrence of the activated complex at higher vibrational levels in measurements at high surface temperatures. The increasing occurrence at higher levels increases the total momentum parallel to the surface plane. This would reduce the anisotropy. The permeation of atoms through sample crystals has frequently been used to supply adspecies at a constant rate for angular and velocity distribution measurements. This method can be applied only at high temperatures. The second factor is the position of adsorption immediately prior to the desorption. Hydrogen adatoms must move to either of the adsorption sites or to the intermediate region to react with each other, since the atom distance in $\mathrm{H}_{2}$ is much less than that of the adsorption sites. No symmetry of the adsorption site for the initial state may be memorized in the angular distribution. The oxidation of $\mathrm{CO}$ has advantages for this kind of study, because it takes place at relatively low temperatures and on oxygen adsorption sites.

\section{SUMMARY}

CO oxidation was studied on $\operatorname{Pd}(110)$ by angle-resolved thermal desorption and low energy electron diffraction. The results are summarized as follows.

(1) $\mathrm{CO}_{2}$ is produced in the temperature range of 110 $500 \mathrm{~K}$, depending on the reactant coverages.

(2) The heating of a coadlayer of $\mathrm{CO}$ and oxygen yields five peaks of $\mathrm{CO}_{2}$ formation.

(3) The desorption in each $\mathrm{CO}_{2}$ peak shows different angular distribution and different crystal azimuth dependence.

(4) $\mathrm{CO}_{2}$ produced in dilute coadlayers indicates an angular distribution with crystal symmetry. The $\mathrm{CO}_{2}$ produced from dense coadlayers loses this symmetry by the collimation effect caused by adsorbates.

\section{ACKNOWLEDGMENT}

This work was supported in part by a Grant-in-Aid for General Scientific Research from the Ministry of Education, No. 62540274.

'G. Comsa and R. David, Surf. Sci. Rep. 5, 145 (1985).

${ }^{2}$ J. A. Baker and D. J. Auerbach, Surf. Sci. Rep. 4, 1 (1984). 
${ }^{3}$ W. van Willigen, Phys. Lett. A 28, 80 (1968).

${ }^{4}$ R. L. Palmer, J. N. Smith, Jr., H. Saltsburg, and D. R. O'Keefe, J. Chem. Phys. 53, 1666 (1970).

${ }^{5}$ T. L. Bradley and R. E. Stickney, Surf. Sci. 38, 313 (1973).

${ }^{6} \mathrm{M}$. Balooch and R. E. Stickney, Surf. Sci. 44, 310 (1974).

${ }^{7}$ M. Balooch, M. J. Cardillo, D.R. Miller, and R. E. Stickney, Surf. Sci. 46, 358 (1974).

${ }^{8}$ A. E. Dabiri, T. J. Lee, and R. E. Stickney, Surf. Sci. 26, 522 (1971).

${ }^{9} \mathrm{G}$. Comsa, R. David, and K. D. Rendulic, Phys. Rev. Lett. 38, 775 (1977); G. Comsa and R. David, Chem. Phys. Lett. 49, 512 (1977).

${ }^{10}$ G. Comsa, R. David, and B. J. Schumacher, Surf. Sci. 85, 45 (1979).

"G. Comsa and R. David, Surf. Sci 117, 77 (1982).

${ }^{12}$ G. Comsa, R. David, and B. J. Schumacher, Surf. Sci. 95, L210 (1980).

${ }^{13}$ R. L. Palmer and J. N. Smith, J. Chem. Phys. 60, 1453 (1974).

${ }^{14}$ C. A. Becker, J. P. Cowin, L. Wharton, and D. J. Auerbach, J. Chem. Phys. 69, 3394 (1977).

${ }^{15}$ C. T. Campbell, G. Ertl, H. Küppers, and J. Segner, J. Chem. Phys. 73, 5862 (1980).

${ }^{16}$ J. Segner, C. T. Campbell, G. Doyen, and G. Ertl, Surf. Sci. 138, 505 (1984).

${ }^{17}$ T. Matsushima, Surf. Sci. 127, 403 (1983).

${ }^{18}$ T. Matsushima, M. Hashimoto, and T. Matsui, J. Chem. Phys. 81, 5151 (1984).

${ }^{19}$ T. Matsushima and H. Asada, Chem. Phys. Lett. 120, 412 (1985); J. Chem. Phys. 85, 1658 (1986).

${ }^{20}$ D. R. Horton and R. I. Masel, Surf. Sci 125, 699 (1983).

${ }^{21}$ T. Matsushima, Z. Phys. Chem. N. F. 158, 175 (1988); 162, 1 (1989).

${ }^{22}$ R. C. Cosser, S. R. Bare, S. M. Francis, and D. A. King, Vacuum 31, 503 (1981).

${ }^{23}$ T. Matsushima, Surf. Sci. 197, L287 (1988).

${ }^{24}$ G. Coma, J. Chem. Phys. 48, 3235 (1968).

${ }^{25}$ H. P. Steinrück, A. Winkler, and K. D. Rendulic, J. Phys. C 17, L311 (1984); Surf. Sci. 152/153, 323 (1985).

${ }^{26}$ H. J. Robota, W. Vielhaber, M. C. Lin, J. Segner, and G. Ertl, Surf. Sci. 155, 101 (1985).

${ }^{27}$ D. O. Hayward and A. D. Taylor, Chem. Phys. Lett. 124, 264 (1986).
${ }^{28}$ C. T. Rettner, H. E. Pfnür, and D. J. Auerbach, Phys. Rev. Lett. 54, 2716 (1985); J. Chem. Phys. 84, 4163 (1986).

${ }^{29}$ M. B. Lee, Q. Y. Yang, and C. T. Ceyer, J. Chem. Phys. 87, 2724 (1987).

${ }^{30}$ A. V. Hamza, H. P. Steinrück, and R. J. Madix, J. Chem. Phys. 86, 6506 (1987); J. Vac. Sci. Technol. A 5, 2768 (1987).

${ }^{31}$ J. D. Beckerle, Q. Y. Yang, A. D. Johnson, and S. T. Ceyer, J. Chem. Phys. 86, 7236 (1987).

${ }^{32}$ H. E. Pfnür, C. T. Rettner, J. Lee, R. J. Madix, and D. J. Auerbach, J. Chem. Phys. 85, 7452 (1986)

${ }^{33}$ M. P. O'Evely, A. V. Hamza, G. E. Gdowski, and R. J. Madix, Surf. Sci. 167, 451 (1986).

${ }^{34}$ T. Toya, Y. Ohno, S. Ishi, and K. Nagai, Proceedings of the 4th International Conference on Solid Surfaces and 3rd European Conference on Surface Science, edited by D. A. Degras and M. Costa (Cannes, 1980), p. 141.

${ }^{35}$ Y. Ohno, T. Toya, S. Ishi, and K. Nagai, Appl. Surf. Sci. 33/34, 238 (1988).

${ }^{36}$ H. Conrad, G. Ertl, J. Koch, and E. Latta, Surf. Sci. 43, 462 (1974).

${ }^{37}$ M. Nishijima, M. Jo, Y. Kuwahara, and M. Onchi, Solid State Commun. 60, 257 (1986).

${ }^{38}$ J. Goschnik, M. Wolf, M. Grunze, J. H. Block, and J. Joboda-Cackovic, Surf. Sci. 178, 831 (1986).

${ }^{39} \mathrm{~J}$. W. He and P. R. Norton, Surf. Sci. 204, 26 (1988).

${ }^{40} \mathrm{~T}$. Matsushima, Surf. Sci. 217, 155 (1989).

${ }^{41} \mathrm{G}$. Ertl and P. Rau, Surf. Sci. 15, 443 (1969).

${ }^{42}$ M. Jo, Y. Kuwahara, M. Onchi, and M. Nishijima, Chem. Phys. Lett. 131, 106 (1986).

${ }^{43}$ J. W. He, U. Memmert, K. Griffiths, W. N. Lennard, and P. R. Norton, Surf. Sci. 202, L555 (1988).

${ }^{44} \mathrm{~J}$. E. Hulse, K. Wandelt, J. Küppers, and G. Ertl, in Proceedings of the 4th International Conference on Solid Surfaces and 3rd ECOSS (Cannes, France 1980), Vol. 1, p. 108.

${ }^{45}$ F. O. Goodman, Surf. Sci. 30, 525 (1972).

${ }^{46} \mathrm{~J}$. F. Wendelken, Surf. Sci. 108, 605 (1981).

${ }^{47}$ W. Heiland, F. Iberl, and E. Taglauer, Surf. Sci. 53, 383 (1975).

${ }^{48}$ C. Backx, C. P. M. de Groot, and P. Biloen, Surf. Sci. 104, 300 (1981). 
The Journal of Chemical Physics is copyrighted by the American Institute of Physics (AIP). Redistribution of journal material is subject to the AIP online journal license and/or AIP copyright. For more information, see http:/ojps.aip.org/jcpo/jcpcr/jsp Copyright of Journal of Chemical Physics is the property of American Institute of Physics and its content may not be copied or emailed to multiple sites or posted to a listserv without the copyright holder's express written permission. However, users may print, download, or email articles for individual use. 